Tropical Journal of Pharmaceutical Research, June 2003; 2 (1): 147-153

(C) Pharmacotherapy Group

Faculty of Pharmacy, University of Benin

Benin City, Nigeria.

All rights reserved.

Available online at http://www.tjpr.freehosting.net

Research Article

\title{
Effects of interacting variables on the tensile strength and the release properties of paracetamol tablets
}

\section{Oluwatoyin A Odeku ${ }^{\Phi}$ and Oludele A Itiola}

Department of Pharmaceutics \& Industrial Pharmacy, University of Ibadan, Ibadan, Nigeria

\begin{abstract}
Purpose: The individual and interaction effects of nature of binder $(N)$, concentration of binder $(C)$ and the relative density $(D)$ on the tensile strength and release properties of paracetamol tablets have been studied using a $2^{3}$ factorial experimental design.

Methodology: Khaya gum, which represented the "low" level, and polyvinylpyrrolidone $(P V P)$, which represented the "high" level, was used as binding agent at concentrations of $0.5 \%$ and $4 \% w / w$ in a paracetamol tablet formulation. The tensile strength, which is a measure of the bond strength of tablets, and the release properties of the tablets- measured by the disintegration and the dissolution times, were used as assessment parameters.

Results: Changing the concentration of binder and the relative density of the tablets from "low" to "high" led to an increase in the tensile strength and the disintegration and dissolution times of the tablets. The ranking of the individual coefficient values for the formulations was $D$ $>N>C$ for $T$ and $C>N>D$ for the disintegration and dissolution parameters while the ranking for the interaction effects was $N-D>N-C>C-D$ for $T$ and $t_{50}, N-C>>-D>C$ - $D$ for $D T$ and $C-D>N-C>>N-D$ for too.

Conclusion: The results suggest that khaya gum could be useful as an alternative binding agent to produce tablets with particular tensile strength and drug release profiles and there was considerable interaction between the variables employed on the tablet properties.
\end{abstract}

Keywords: Binding agent, khaya gum, release properties, paracetamol tablets, tensile strength

\footnotetext{
$\Phi$ To whom correspondence should be addressed: E-mail: odeku@skannet.com Tel: 234208106403
} 


\section{Introduction}

The tensile strength, which is a measure of the bond strength of tablets, is an indicator of the ability of the tablet to withstand the rigours of handling involved in manufacture, transportation, dispensing and usage of pharmaceutical tablets. However, the tablet must be able to release the drug content in the GIT for absorption. Thus, the tensile strength of a tablet plays a vital role in the release of the drug from the formulations. The release properties of drug from the tablet formulations can be quantified by the disintegration and the dissolution times of the tablet. It is well known that, for disintegrating tablets, considerable dissolution of drug can take place before complete disintegration of the tablets, a phenomenon which depends largely on the mechanism of disintegration and certain physicochemical properties of the drug, such as its solubility. The physicochemical properties of tablets have been shown to depend considerably on the nature and concentration of the binding agent employed in the formulation and also on the relative density of the tablet ${ }^{1-4}$. Thus, the relationship between these parameters for particular drugs is of interest and the quantitative effects of important formulation and processing variables on these parameters are very important.

In an effort to produce tablets of important drugs such as paracetamol from locally available materials, khaya gum obtained from the incised trunk of the tree Khaya grandifolia (also called Khaya grandifoliola), Family Meliaceae, has been investigated as a binding agent in tablet formulations $s^{4,5}$. The gum has been found to be useful as a binding agent for particular tablet formulations but the quantitative effects of important formulation and processing variables on the tensile strength and release properties of the tablet appear to be largely uninvestigated. In the present work, a study has been made of the relative quantitative effects of nature (khaya gum and PVP) and concentration of binding agent, and the relative density of the tablets on the tensile strength $(T)$, the disintegration time (DT) and dissolution parameters - $t_{50}$ and $t_{90}$ (the time required for $50 \%$ and $90 \%$ of paracetamol to be dissolved respectively) of paracetamol tablets using a factorial experimental design ${ }^{6}$ which has already proved useful in the analysis of the quantitative individual and interaction effects of various formulation factors on the disintegration and dissolution rate of tablets ${ }^{3,7}$. Paracetamol, a widely used analgesic and antipyretic agent, cannot be made into satisfactory tablets due to its capping and lamination tendencies. It is normally produced commercially as tablets containing $500 \mathrm{mg}$ of the drug with added excipients such as a binding agent to modify its plastic and elastic properties.

\section{Materials and methods}

\section{Materials}

The materials used were paracetamol BP and corn starch BP (BDH Chemicals Ltd., Poole, U.K), lactose (DMV Veghel, Netherlands), gelatin BP (Hopkin \& Williams, Chadwell Heath, Essex, U.K), PVP (mw, 40,000; Aldrich Chemicals Co. Ltd, Gillingham, Dorset, U. K) and khaya gum from Khaya grandifolia (Botanical Gardens, University of Ibadan, Ibadan, Nigeria). A description of the collection and purification of khaya gum has been given elsewhere ${ }^{4}$.

\section{Preparation of granules}

Batches $(250 \mathrm{~g})$ of a basic formulation of paracetamol $(83 \% \mathrm{w} / \mathrm{w})$, lactose $(10 \% \mathrm{w} / \mathrm{w})$ and corn starch $(7 \% \mathrm{w} / \mathrm{w})$ were dry-mixed for $5 \mathrm{~min}$ in a Kenwood planetary mixer and then moistened with either $31 \mathrm{ml}$ of distilled water or the prepared binder solutions of PVP or mucilages of Khaya gum to produce granules containing different concentrations of the binders. Massing was continued for $5 \mathrm{~min}$ and the wet masses were granulated by passing them manually through a number 12 mesh sieve $(1400 \mu \mathrm{m})$, dried in a hot air oven for 18 $\mathrm{hr}$ at $50^{\circ} \mathrm{C}$ and then resieved through a number 16 mesh sieve $(1000 \mu \mathrm{m})$. The 
moisture content of the granule formulations as determined with an Ohaus moisture balance (Ohaus Scale Corporation, USA) was between 1.1 and $1.8 \% \mathrm{w} / \mathrm{w}$. Particle densities were determined by the pycnometer method with xylene as the displacement fluid. The degree of mixing of the granules from three different regions of each formulation batch was determined by spectrophotometric assay of paracetamol in quadruplicate at $249 \mathrm{~nm}$. In each case, the degree of mixing was found to be $>0.95$.

\section{Preparation of tablets}

Quantities $(500 \mathrm{mg})$ of granules of the formulations, giving a tablet thickness of 4.37 $\pm 0.02 \mathrm{~mm}$ at zero porosity as calculated from particle density values, were compressed for 1 min with predetermined loads using a Carver hydraulic hand press (Model C, Carver Inc., Menomonee falls, Wisconsin, USA). Before each compression, the die $(10.5 \mathrm{~mm}$ diameter) and the flat-faced punches were lubricated with a $2 \% \mathrm{w} / \mathrm{v}$ dispersion of magnesium stearate in ethanol: ether (1:1). After ejection, tablets were stored over silica gel for $24 \mathrm{hr}$ to allow for elastic recovery and hardening and prevent falsely low yield values. The weights, $\mathrm{W}$, and dimensions were then determined to within $\pm 1 \mathrm{mg}$ and $0.01 \mathrm{~mm}$ respectively, and the relative densities, D, were calculated using the equation:

$$
D=W / V_{t} \cdot \rho_{s}
$$

where $V_{t}$ is the volume of tablet (including the hole when present) in $\mathrm{cm}^{3}$ and $\rho_{\mathrm{s}}$ is the particle density of the solid material in $\mathrm{g} / \mathrm{cm}^{3}$.

\section{Tensile strength of tablets}

The tensile strengths, $\mathrm{T}$, of the tablets were determined at room temperature by diametral compression using a PTB 301 hardness tester (Pharmatest, Switzerland) and applying the equation':

$$
\mathrm{T}=2 \mathrm{~F} / \pi \mathrm{dt}
$$

where $\mathrm{T}$ is the tensile strength of the tablet $\left(\mathrm{MNm}^{-2}\right), \mathrm{F}$ is the load (MN) needed to cause fracture, $d$ is the tablet diameter $(m)$, and $t$ is the tablet thickness $(m)$. Results were taken only from tablets which split cleanly into two halves without any sign of lamination. All measurements were made in triplicate or more and the results given are the mean of several determinations.

\section{Disintegration test}

The disintegration times, DT, of the tablets were determined in distilled water at $37 \pm 0.5^{\circ}$ C using an Apex disintegration testing apparatus (Apex Construction Ltd.; Northflect gravesent and Dartford, Kent, UK). The time taken for all the tablets to disintegrate and go through the wire mesh was recorded. Determinations were made in triplicate.

\section{Dissolution test}

The dissolution rates of the tablets were determined at $37 \pm 0.5^{\circ} \mathrm{C}$ in 1 litre of $0.1 \mathrm{M}$ $\mathrm{HCl}$ using an Erweka dissolution rate machine (Erweka Apparatabau, Gmbh Heusenstamm kr. Offenbach/Main, Germany) and a stirring speed of 100 revolutions per min (USP XX). The amount of paracetamol that had dissolved after a certain period was determined spectrophotometrically at $249 \mathrm{~nm}$ using a Lambda 3B UV/visible spectrophotometer (Perkin - Elmer, USA) replacing the sample with an equal volume of $0.1 \mathrm{M} \mathrm{HCl}$ at the same temperature in order to keep the volume of the dissolution medium constant during the course of the test.

All determinations were made in triplicate or more and the results given are the means of several determinations.

\section{Experimental design}

To study the effect of nature of binding agent (denoted by $\mathrm{N}$ ), concentration of binding agent (denoted by $\mathrm{C}$ ) and relative density of the tablet (denoted by $\mathrm{D}$ ) on the tensile strength, and the disintegration and dissolution times of the tablets, the experiments were performed in

149 Trop J Pharm Res, June 2003; 2 (1) 
a factorial design, which involved the application of simple statistics ${ }^{7}$. The basis of the experimental design was that each of the three variables was utilized at a "high" level (denoted by the subscript, $\mathrm{H}$ ) and a "low" level (denoted by the subscript, L). The number of experiments in the design was $2^{3}$ i.e, 8.

Using the above nomenclature the various combinations between the variables used in the design were;

$$
\begin{array}{llll}
N_{L} C_{L} D_{L}, & N_{L} C_{H} D_{L}, & N_{L} C_{H} D_{H}, & N_{L} C_{L} D_{H} \\
N_{H} C_{L} D_{L}, & N_{H} C_{H} D_{L}, & N_{H} C_{H} D_{H}, & N_{H} C_{L} D_{H}
\end{array}
$$

$\mathrm{N}_{\mathrm{L}}=$ Nature of binding agent (khaya gum)

$\mathrm{N}_{\mathrm{H}}=$ Nature of binding agent (PVP)

$\mathrm{C}_{\mathrm{L}}=$ Concentration of binder $(0.5 \% \mathrm{w} / \mathrm{w})$

$\mathrm{C}_{\mathrm{H}}=$ Concentration of binder $(4.0 \% \mathrm{w} / \mathrm{w})$

$D_{L}=$ Relative density of 0.8

$\mathrm{D}_{\mathrm{H}}=$ Relative density of 0.9

By grouping the results into a number of sets it was possible to assess the effects that each of the three variables had separately on the tensile strength, and the disintegration and dissolution times of the tablets and also to determine whether the variables were interacting or acting independently of each other.

The effects of increasing N, from its "low" level to its "high" level on the tensile strength, and the disintegration and dissolution times were found by summing all tensile strength (or the disintegration or dissolution time) results of samples containing "high" level of $\mathrm{N}$ and subtracting the sum of the results of samples containing "low" levels of $\mathrm{N}$. That is;

$1 / 4\left[\left(\mathrm{~N}_{\mathrm{H}} \mathrm{C}_{\mathrm{L}} \mathrm{D}_{\mathrm{L}}+\mathrm{N}_{\mathrm{H}} \mathrm{C}_{\mathrm{H}} \mathrm{D}_{\mathrm{L}}+\mathrm{N}_{\mathrm{H}} \mathrm{C}_{\mathrm{H}} \mathrm{D}_{\mathrm{H}}+\mathrm{N}_{\mathrm{H}} \mathrm{C}_{\mathrm{L}} \mathrm{D}_{\mathrm{H}}\right)-\right.$ $\left.\left(N_{L} C_{L} D_{L}+N_{L} C_{H} D_{L}+N_{L} C_{H} D_{H}+N_{L} C_{L} D_{H}\right)\right]$

The amount by which the result of this treatment departed from zero (irrespective of whether positive or negative) was a quantitative measure of the effect of $\mathrm{N}$ tensile strength (or the disintegration or dissolution times) of the tablet. Similar expressions were used for finding the effects of $C$ and $P$.
To determine whether there was any interaction between two variables, the result of the combinations in which they appear together at either "high" or "low" levels were summed and the sum of other combinations subtracted from this to obtain the interaction coefficient.

For $\mathrm{N}$ and $\mathrm{C}$ :

$1 / 4\left[\left(\mathrm{~N}_{\mathrm{L}} \mathrm{C}_{\mathrm{L}} \mathrm{D}_{\mathrm{L}}+\mathrm{N}_{\mathrm{L}} \mathrm{C}_{\mathrm{L}} \mathrm{D}_{\mathrm{H}}+\mathrm{N}_{\mathrm{H}} \mathrm{C}_{\mathrm{H}} \mathrm{D}_{\mathrm{H}}+\mathrm{N}_{\mathrm{H}} \mathrm{C}_{\mathrm{H}} \mathrm{D}_{\mathrm{L}}\right)\right.$

$\left.\left(\mathrm{N}_{L} \mathrm{C}_{H} D_{L}+\mathrm{N}_{L} \mathrm{C}_{H} D_{H}+\mathrm{N}_{H} \mathrm{C}_{L} D_{L}+N_{H} C_{L} D_{H}\right)\right]$

A result of zero indicates no interaction, but if the interaction coefficient was significantly removed from zero, it is concluded that the two variables concerned were interacting with each other. The extent of removal from zero is a measure of the magnitude of interaction ${ }^{7}$. Similar expressions were used for estimating the interaction between $\mathrm{N}$ and $\mathrm{D}$, and between $\mathrm{C}$ and $\mathrm{D}$

\section{Results and Discussion}

Representative plots of tensile strength $(T)$ and disintegration time (DT) versus relative density (D) for paracetamol tablets containing $4 \% \mathrm{w} / \mathrm{w}$ of the binders are presented in Figures 1 and 2 respectively while the plots of percentage of paracetamol dissolved versus time for paracetamol tablets compressed at relative density 0.9 are presented in Figure 3. The values of tensile strength and the disintegration and dissolution times at two selected relative densities of 0.8 and 0.9 , which is representative of the range of relative density normally achieved for commercial paracetamol tablets, for the factorial experiments are given in Table 1. These values were used to calculate the individual and interaction coefficients for the variables using equations (5) and (6). The coefficient values are presented in Table 2 . The individual and interaction effects provide a clear indication of the quantitative effects of the three variables studied on the tensile strength, the disintegration and dissolution times of the paracetamol tablets. 


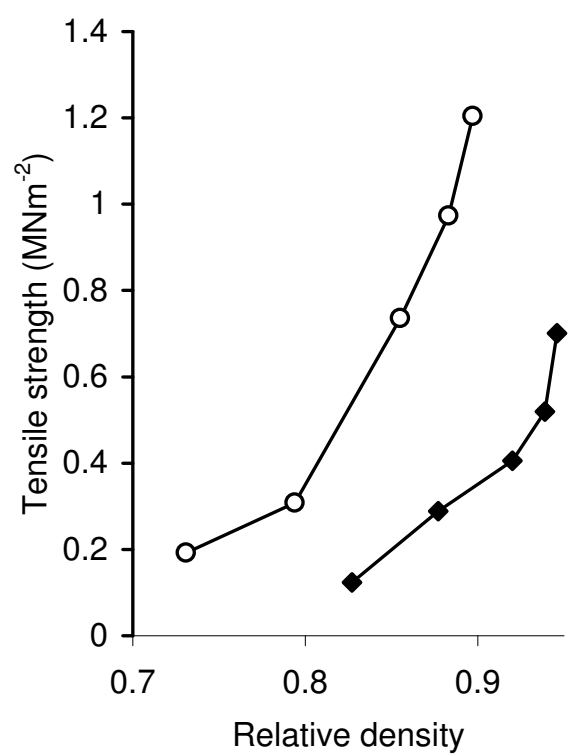

Figure 1: Tensile strength versus relative density for paracetamol tablets containing $4 \%$ w/w of binder. O, khaya gum; , PVP

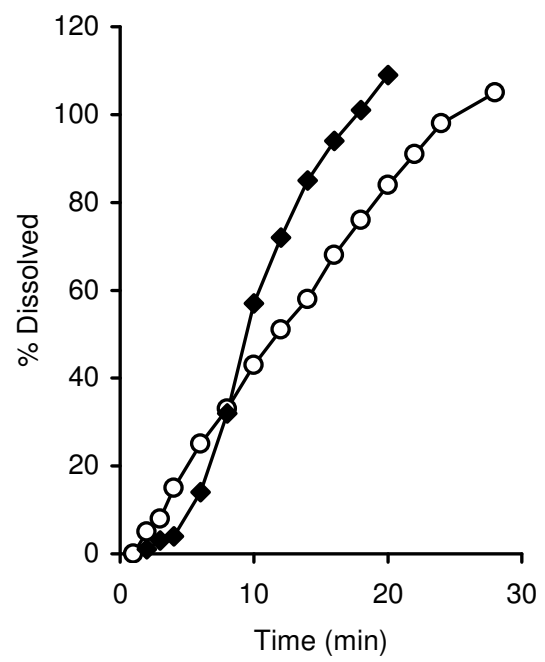

Figure 3: Dissolution profiles of paracetamol tablets compressed at relative density 0.9 . O, khaya gum; PVP

In comparing the formulations, the ranking of the individual (independent) coefficient values (Table 2) for the formulations was $D>$ $\mathrm{N}>\mathrm{C}$ for $\mathrm{T}$ and $\mathrm{C}>\mathrm{N}>\mathrm{D}$ for the disintegration and dissolution parameters. It

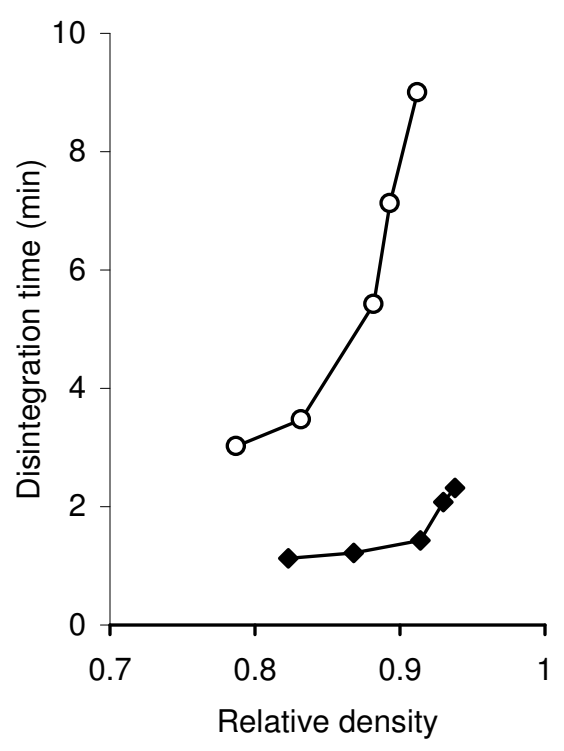

Figure 2: Disintegration time versus relative density for paracetamol tablets containing $4 \% \mathrm{w} / \mathrm{w}$ of binder. O, khaya gum; $\bullet$ PVP

can be seen that all the individual effects were positive indicating that all the values of the parameters increased. The effect of $C$ indicates that increasing the concentration of the plastoelastic binder from $0.5 \%$ to $4.0 \%$ $\mathrm{w} / \mathrm{w}$ led to an increase in the plastic deformation of the formulation during compression and subsequently to the formation of more solid bonds in the tablet leading to an increase in tensile strength and the disintegration and dissolution times of the tablet. In general, the concentration of binder, $\mathrm{C}$ had the lowest effect on $\mathrm{T}$ but the highest effect on the disintegration and dissolution times of the tablets. The manifestations of the effects of $\mathrm{C}$ concerning tablet properties usually tends to be strongly related to those other formulation variables and should therefore be given particular consideration when developing tablet formulations.

The effect of $D$ on all the parameters was positive although $D$ had the highest effect on the tensile strength of the tablet but the least effect on the disintegration and dissolution 
Table 1: Tensile strength $\left(\mathrm{MNm}^{-2}\right)$, disintegration and dissolution times (min) for paracetamol tablets for factorial experimental design

\begin{tabular}{ccccc}
$\begin{array}{c}\text { Variables \& } \\
\text { combina- } \\
\text { tion codes }\end{array}$ & $\begin{array}{c}\mathrm{T} \\
\left(\mathrm{MNm}^{-2}\right)\end{array}$ & $\begin{array}{c}\mathrm{DT} \\
(\mathrm{min})\end{array}$ & $\begin{array}{c}\mathrm{t}_{50} \\
(\mathrm{~min})\end{array}$ & $\begin{array}{c}\mathrm{t}_{90} \\
(\mathrm{~min})\end{array}$ \\
\hline $\mathrm{N}_{\llcorner} \mathrm{C}_{\llcorner} \mathrm{D}_{\llcorner}$ & 0.16 & 0.26 & 4.70 & 8.00 \\
$\mathrm{~N}_{\llcorner} \mathrm{C}_{\llcorner} D_{H}$ & 0.73 & 0.56 & 7.95 & 11.20 \\
$\mathrm{~N}_{\llcorner} C_{H} D_{\llcorner}$ & 0.38 & 3.10 & 11.20 & 19.50 \\
$\mathrm{~N}_{\llcorner} C_{H} D_{H}$ & 1.18 & 5.05 & 13.70 & 24.00 \\
$\mathrm{~N}_{H} C_{\llcorner} D_{\llcorner}$ & 0.46 & 0.45 & 3.00 & 7.20 \\
$\mathrm{~N}_{H} C_{\llcorner} D_{H}$ & 1.43 & 0.57 & 4.10 & 8.75 \\
$\mathrm{~N}_{H} C_{H} D_{\llcorner}$ & 1.14 & 1.02 & 8.50 & 11.20 \\
$\mathrm{~N}_{H} C_{H} D_{H}$ & 2.38 & 1.36 & 10.20 & 16.70 \\
\hline
\end{tabular}

times. Thus, increasing the relative density from 0.8 to 0.9 led to an increase in the tensile strength of the tablet and the disintegration and dissolution times. This can be due to the fact that as the relative density of the tablet increased, more solid bonds will be formed between the particles leading to an increase in tensile strength. Furthermore, the binding agents are forced into interparticular spaces, thereby increasing the area of contact between particles leading to the formation of additional solid bonds and thus an increase in the disintegration and dissolution times of the tablets. This can be attributed to the reduction in the size of the capillary spaces between the particles which reduced the rate of penetration of water into the tablet to effect bond separation ${ }^{10}$.

The influence of $\mathrm{N}$ on the tensile strength of the tablets was positive which indicates that tablets containing PVP as binder had higher tensile strength than tablets containing khaya gum. On the other hand, the influence of $\mathrm{N}$ on the disintegration and dissolution times was negative indicating that khaya gum, which represented the "low" level produced tablets with longer disintegration and dissolution times than PVP, which represented the "high" level of $\mathrm{N}$. Thus while tablets containing khaya gum as binding agent had lower tensile strength, it also had
Table 2: Individual effects of relative density (D), concentration of binder (C) and nature of binder $(\mathrm{N})$ on the tensile strength, and the disintegration and dissolution times of paracetamol tablets

\begin{tabular}{ccccc}
\hline Variables & $\mathrm{T}$ & $\mathrm{DT}$ & $\mathrm{t}_{50}$ & $\mathrm{t}_{90}$ \\
\hline \multicolumn{5}{c}{ Independent coefficient } \\
$\mathrm{N}$ & 0.74 & -1.39 & -2.94 & -4.71 \\
$\mathrm{C}$ & 0.57 & 2.17 & 5.96 & 9.11 \\
$\mathrm{D}$ & 0.90 & 0.68 & 2.14 & 3.69
\end{tabular}

Interaction coefficient

\begin{tabular}{lllll} 
N - C & 0.24 & -1.62 & -0.16 & -3.09 \\
N - D & -0.90 & -0.68 & -0.74 & -0.16 \\
C - D & 0.12 & 0.47 & -0.04 & 3.81 \\
\hline
\end{tabular}

longer disintegration and dissolution times than those containing PVP. However, all the tablets complied with the BP (1980) requirement on disintegration (i.e. disintegration within 15 minutes). Thus, khaya gum could be useful as an alternative binding agent to produce tablets with particular tensile strength and drug release profiles.

The interaction coefficient values (Table 2) indicate the effect of the variables in combination. For the formulations, the ranking of the effects on $T$ and $t_{50}$ was $\mathrm{N}-\mathrm{D}$ $>\mathrm{N}-\mathrm{C}>\mathrm{C}-\mathrm{D}$, on DT was $\mathrm{N}-\mathrm{C}>\mathrm{N}$ $\mathrm{D}>\mathrm{C}-\mathrm{D}$, and on $\mathrm{t}_{90}$ was $\mathrm{C}-\mathrm{D}>\mathrm{N}-\mathrm{C}>>\mathrm{N}$ $D$. The magnitude of the interaction effects show that there were generally considerable interactions between the concentration of binder, $\mathrm{C}$ and the other two variables, $\mathrm{N}$ and $D$. This is probably due to the fact that binding agents being plastoelastic in nature undergoes extensive plastic deformation under high compressional forces to form strong solid bonds between particles, the number of bonds formed depending considerably on the concentration of binder employed. The manifestations of the effect of $\mathrm{C}$, concerning tablet properties, have been shown to be strongly related to the relative 
density of the tablet, $\mathrm{D}$ and the nature of the binding agent, $\mathrm{N}$ employed in the formulation ${ }^{3,6,10}$. Thus, the nature of binder $(\mathrm{N})$, concentration of binder $(\mathrm{C})$ and relative density (D) employed in a formulation need to be carefully chosen to enable the production of tablets with the adequate bond strength to withstand the rigors of handling and afford the release of the drug in the desired time period and with the desired disintegration/ dissolution profile.

\section{Conclusion}

The results suggest that khaya gum could be useful as an alternative binding agent to produce tablets with particular tensile strength and drug release profiles. Furthermore, there was considerable interaction between the variables for the different binding agents as evidenced by the magnitude of the individual and interaction coefficient employed on the tensile strength and the disintegration and dissolution times of paracetamol tablets. The concentration of binder, C, appears to be the most influential variable in this case, indicating that any attempt to manipulate the tensile strength or the disintegration and dissolution times of the tablets should start with a consideration of C. This study would be useful in developing tablet formulations for other drugs as well.

\section{References}

1. Itiola OA, Pilpel N. Studies on metronidazole tablet formulations. J Pharm Pharmacol 1986; 38: 816.

2. Itiola $O A$. The effects of interating variables on the tensile strength of lactose powder and compacts. Polytec J Sci Tech 1990; 1: 7-19.

3. Itiola $O A$, Pilpel N. Formulation effects on the mechanical properties of metronidazole tablets. J Pharm Pharmacol 1991; 43: 145-7.

4. Odeku OA, Itiola OA. Evaluation of khaya gum as a binder in a paracetamol tablet formulation. Pharm Pharmacol Commun 1998; 4: 183-8.

5. Odeku OA, Itiola OA. Effects of interacting variables on the friability and disintegration of griseofulvin tablets. Nig J Sci 1996; 30: 205-12.

6. Woolfall RC. An approach to product formulation. Soap Perfum Cosmet 1964; 37: 965-970.

7. Itiola OA, Pilpel N. Effects of interacting variables on the disintegration and dissolution of metronidazole tablets. Pharmazie 1996; 51: 987-9.

8. Walter $\mathrm{L}$ (ed) The Pharmaceutical Codex: Principles and Practice of Pharmaceutics. $12^{\text {th }}$ edition. London: The Pharmaceutical Press, 1994 pp. 509-27.

9. Fell JT, Newton JM. Determination of tablet strength by diametral - compression test. J Pharm Sci 1970; 59: 688-691.

10. Itiola OA, Pilpel N. Tableting characteristics of metronidazole formulations. Int J Pharm 1986; 31: $99-105$ 